Author affiliations and support information (if applicable) appear at the end of this article.

Published at jco.org on May 1, 2017.

Reprint requests: 2318 Mill Road, Suite 800, Alexandria, VA 22314; e-mail: cancerpolicy@asco.org.

Corresponding author: Karen M. Winkfield, MD, PhD, Wake Forest Baptist Medical Center, Department of Radiation Oncology, Comprehensive Cancer Center, Medical Center Boulevard, Winston-Salem, NC 27157; e-mail: kwinkfie@wakehealth.edu.

(C) 2017 by American Society of Clinical Oncology

$0732-183 X / 17 / 3522 w-2576 w / \$ 20.00$

\title{
American Society of Clinical Oncology Strategic Plan for Increasing Racial and Ethnic Diversity in the Oncology Workforce
}

Karen M. Winkfield, Christopher R. Flowers, Jyoti D. Patel, Gladys Rodriguez, Patricia Robinson, Amit Agarwal, Lori Pierce, Otis W. Brawley, Edith P. Mitchell, Kimberly T. Head-Smith, Dana S. Wollins, and Daniel F. Hayes

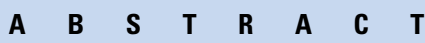

In December 2016, the American Society of Clinical Oncology (ASCO) Board of Directors approved the ASCO Strategic Plan to Increase Racial and Ethnic Diversity in the Oncology Workforce. Developed through a multistakeholder effort led by the ASCO Health Disparities Committee, the purpose of the plan is to guide the formal efforts of ASCO in this area over the next three years (2017 to 2020). There are three primary goals: (1) to establish a longitudinal pathway for increasing workforce diversity, (2) to enhance ASCO leadership diversity, and (3) to integrate a focus on diversity across ASCO programs and policies. Improving quality cancer care in the United States requires the recruitment of oncology professionals from diverse backgrounds. The ASCO Strategic Plan to Increase Racial and Ethnic Diversity in the Oncology Workforce is designed to enhance existing programs and create new opportunities that will move us closer to the vision of achieving an oncology workforce that reflects the demographics of the US population it serves.

\section{J Clin Oncol 35:2576-2579. (C) 2017 by American Society of Clinical Oncology}

\section{INTRODUCTION}

Cancer disparities are unfavorable differences in cancer incidence, outcome, and burden of disease that exist among specific populations in the United States. ${ }^{1}$ Significant progress has been made to reduce cancer mortality for all populations; however, black men and women in the United States bear the greatest burden of disease, having the highest incidence and mortality rates for common cancers, such as lung, colorectal, and prostate cancers. ${ }^{2}$ A 2015 American Cancer Society report suggests that the breast cancer mortality gap between black and white women has actually widened over the past few years. ${ }^{3}$ Similar disparities exist in other cancer types and for other racial and ethnic populations. The factors contributing to racial and ethnic disparities in cancer outcomes are complex and interrelated, ${ }^{4}$ but lack of access to high-quality care that is understanding and respectful of diverse traditions and cultures plays a significant role. ${ }^{5,6}$

As the US population becomes more diverse, increasing the racial and ethnic diversity of health care providers is essential to ensure high-quality cancer care is delivered to our burgeoning minority communities in a manner that honors their values. Developing a physician workforce that reflects the diversity in the United States will improve attitudes toward and awareness of minorities in health care institutions, bring increased intercultural responsiveness, and engender trust and comfort in patients, particularly in communities that have traditionally been underserved. A diverse oncology workforce will help expand health care access, foster research and discovery in minority populations, and influence policymakers to meet the needs of a growing heterogeneous population. Therefore, improving quality cancer care in the United States requires the recruitment of oncology professionals from diverse backgrounds.

\section{CURRENT STATE OF AND TRENDS IN RACIAL} AND ETHNIC DIVERSITY IN ONCOLOGY

The National Academy of Medicine (formerly the Institute of Medicine) has long recognized the need to diversify the physician workforce as a way to improve health disparities. ${ }^{7}$ Physicians from backgrounds that are underrepresented in medicine (URM) are even more poorly represented in oncologic subspecialties when compared with other areas of medicine. The Association of 
American Medical Colleges defines URM as "those racial and ethnic populations that are underrepresented in the medical profession relative to their numbers in the general population." Historically, the designation solely included "blacks, Mexican Americans, Native Americans (that is, American Indians, Alaska Natives, and Native Hawaiians), and mainland Puerto Ricans." 8 The definition was changed in 2003 in recognition of changing US demographics; however, the racial and ethnic groups noted still remain the most URM. ${ }^{9}$ For the purposes of this strategic plan, races and ethnicities that have been identified as URM include but are not limited to American Indian/Alaska Native, black/African American, Hispanic/Latino, and Native Hawaiian/Other Pacific Islander.

In an effort to assess the current trends in the oncologic workforce, ASCO has compiled data evaluating the race and ethnicity of trainees, practicing physicians, and its own members. The proportion of black/African American and Hispanic/Latino oncology fellows is consistently lower than many of the other internal medicine subspecialty fellowships. ${ }^{10}$ According to the most recent census, $13 \%$ of the US population is black or African American, and $18 \%$ is Hispanic or Latino. ${ }^{11}$ In contrast, of the physician workforce practicing oncology, only $2.3 \%$ self-identified as black or African American, and 3\% self-identified as Hispanic or Latino ${ }^{12}$ (Fig 1). The demographics of the ASCO membership are similar to the national statistics of practicing oncologists, with $2.38 \%$ and $3.08 \%$ of members self-identifying as black or African American and Hispanic, respectively.

\section{BARRIERS TO DIVERSIFICATION}

Although the distribution of medical students is not reflective of the racial or ethnic demographics of the US population, ${ }^{11}$ the number of URM trainees in oncology is still lower than one might expect. Several factors may be negatively affecting the selection of oncology as a medical specialty for trainees. These factors include limited exposure to oncologic specialties during medical school ${ }^{17}$ and the fact that oncology training for medical students often focuses on the inpatient setting, giving students an uneven view of the specialty.

Additional barriers exist that are specific to URM students enrolled in medical school. An important barrier is insufficient URM role models. ${ }^{18}$ The lack of oncology faculty from

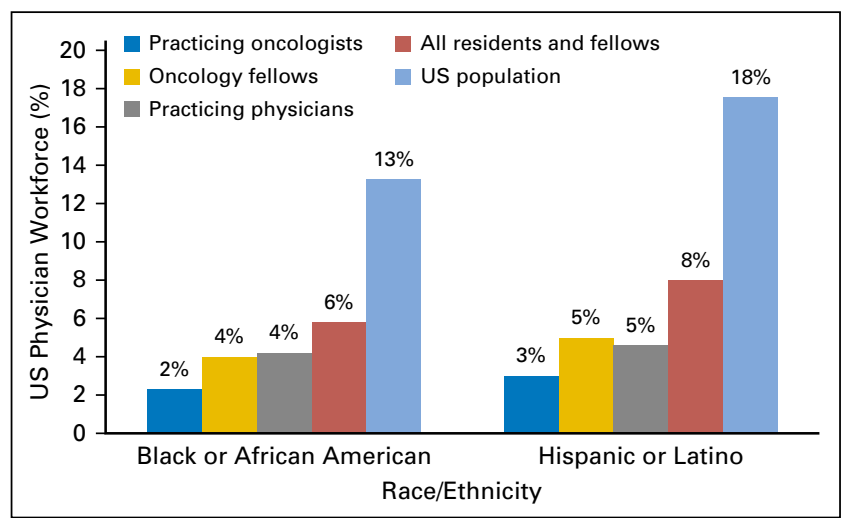

Fig 1. Physicians, fellows, and US population by race and ethnicity. Data adapted. ${ }^{13-16}$ backgrounds that are traditionally URM may affect specialty selection. Additionally, because evidence shows that oncologists' unconscious or implicit racial bias is negatively associated with oncologist communication and patients' reactions to racially discordant oncology interactions, ${ }^{6}$ implicit bias may also influence the selection of oncology training program trainees, irrespective of qualifications.

\section{ASCO WORKFORCE DIVERSITY EFFORTS AND GOALS}

For the last several years, ASCO has engaged in efforts designed to support and promote diversity in the oncology workforce, primarily through the Diversity in Oncology Initiative (DOI) programs. Developed by the ASCO Health Disparities Committee and funded through the Conquer Cancer Foundation of ASCO, the DOI consists of award opportunities for medical students and residents who self-identify as URM. Two award opportunities are available: (1) the Medical Student Rotation provides clinical or clinical research oncology rotations for US medical students from URM backgrounds (a mentoring component is included whereby the award recipient is paired with a clinical oncologist who provides ongoing academic and career guidance), and (2) the Resident Travel Award provides financial support for URM residents to attend the ASCO Annual Meeting. Since its inception in 2008, the program has awarded more than $\$ 1.1$ million in funding to 136 recipients at more than 90 different institutions nationwide. To date, 105 awardees have become ASCO members, and some are active volunteers, serving on various committees. This outcomebased strategic plan for workforce diversity in oncology was developed to help guide the overall workforce diversity efforts of ASCO, including DOI programs.

\section{STRATEGIC PLAN DEVELOPMENT}

The ASCO Health Disparities Committee partnered with representatives from the ASCO Professional Development Committee and Workforce Advisory Group, along with other ASCO stakeholders. A Workforce Diversity Strategic Planning Retreat was held in February 2016 to help build consensus around workforce diversity, identify measureable and attainable goals, and brainstorm for best practices to achieve these goals. During the retreat, a diverse group of experts reviewed strategies from other physician organizations, as well as successful models of workforce diversity outside of medicine, to help generate ideas for the ASCO strategic plan. The retreat summary outlined recommended goals, objectives, and outcomes, which formed the basis of the ASCO Strategic Plan to Increase Racial and Ethnic Diversity in the Oncology Workforce (2017 to 2020). The strategic plan was reviewed and approved by the ASCO Board of Directors on December 14, 2016.

ASCO STRATEGIC PLAN TO INCREASE RACIAL AND ETHNIC DIVERSITY IN THE ONCOLOGY WORKFORCE (2017 TO 2020)

The ASCO 3-year strategic plan for increasing racial and ethnic diversity in the oncology workforce in the United States is 
summarized in Table 1 . There are three primary goals: (1) to establish a longitudinal pathway for increasing workforce diversity, (2) to enhance ASCO leadership diversity, and (3) to integrate a focus on diversity across ASCO programs and policies. The strategic plan is designed to enhance existing programs and create new opportunities that will move us closer to the vision of achieving an oncology workforce that reflects the demographics of the US population it serves. The plan has been developed to establish short-term goals, achievable within 3 years, that will fulfill the mission to promote the development of an oncology workforce that is culturally competent and equipped to care for disparate populations.

The first goal is focused on improving the pathway to oncology for medical trainees; the remaining two goals focus on
ASCO as an organization. As noted by the American College of Radiology, successful diversity programming "will be preceded by embracing diversity and inclusion as core values central to the mission, senior leadership demonstrating long-term commitment to diversity goals, [and] building diversity from the top down." 18 (p1424) In addition to providing a visible example and leadership, ASCO acknowledges that to provide the best care for our changing nation, workforce diversity within the society and its leadership will help drive innovative strategies that will allow us to keep pace with our changing society.

In conclusion, ASCO is committed to actively engaging in efforts to reduce disparities in cancer care and outcome; therefore, workforce diversity is important to the organization. As the voice of

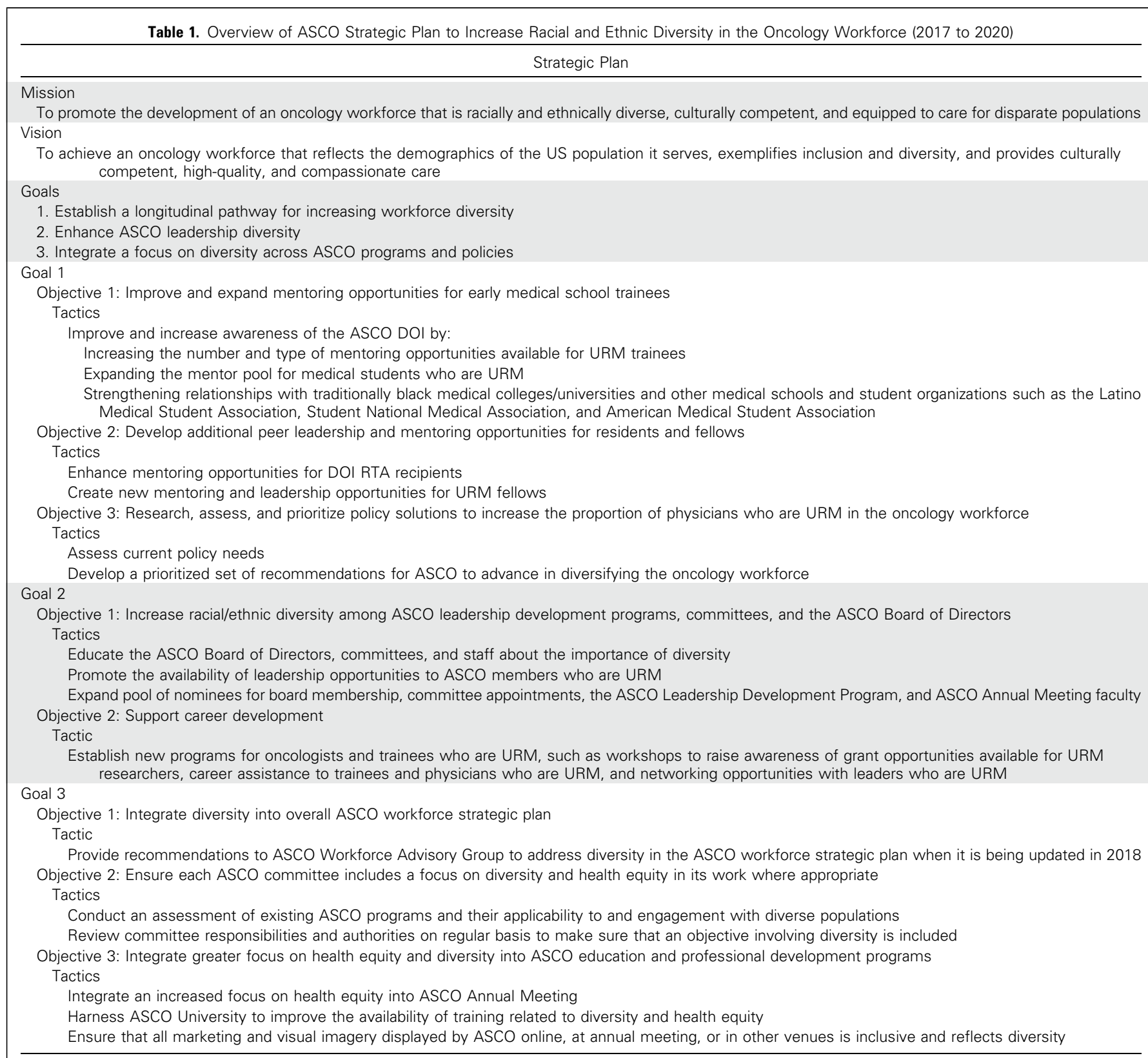

Abbreviations: ASCO, American Society of Clinical Oncology; DOI, Diversity in Oncology Initiative; RTA, Resident Travel Award; URM, underrepresented in medicine. 
cancer care providers and the patients they serve, ASCO will continue to work to advance access and delivery of high-quality cancer care for all patients regardless of their race or ethnicity. ASCO will collaborate with stakeholders across the cancer community to achieve greater racial and ethnic diversity in the oncology workforce and in the work of the society.

To begin the implementation of the ASCO Strategic Plan to Increase Racial and Ethnic Diversity in the Oncology Workforce (2017 to 2020), ASCO has convened a work group comprising members of the ASCO Health Disparities Committee, Professional Development Committee, and Workforce Advisory Group. Members of this work group along with ASCO staff will be responsible for overseeing the implementation of this strategic plan, determining measurable outcomes, and assigning roles and responsibilities. Progress will be reviewed annually and reported to the ASCO Board of Directors, Health Disparities Committee,
Professional Development Committee, and Workforce Advisory Group as well as other appropriate bodies identified by the work group.

\section{AUTHORS' DISCLOSURES OF POTENTIAL CONFLICTS OF INTEREST}

Disclosures provided by the authors are available with this article at jco.org.

\section{AUTHOR CONTRIBUTIONS}

Administrative support: Kimberly T. Head-Smith, Dana S. Wollins Manuscript writing: All authors

Final approval of manuscript: All authors

\section{REFERENCES}

1. O'Keefe EB, Meltzer JP, Bethea TN: Health disparities and cancer: Racial disparities in cancer mortality in the United States, 2000-2010. Front Public Health 3:51, 2015

2. DeSantis $C E$, Siegel $R L$, Sauer $A G$, et al: Cancer statistics for African Americans, 2016: Progress and opportunities in reducing racial disparities. CA Cancer J Clin 66:290-308, 2016

3. DeSantis CE, Fedewa SA, Goding Sauer A, et al: Breast cancer statistics, 2015: Convergence of incidence rates between black and white women. CA Cancer J Clin 66:31-42, 2016

4. Centers for Disease Control and Prevention: Factors that contribute to health disparities in cancer. https://www.cdc.gov/cancer/healthdisparities/basic_ info/challenges.htm

5. American Cancer Society: Breast cancer facts \& figures. http://www.cancer.org/research/cancer-factsstatistics/breast-cancer-facts-figures.html
6. Penner LA, Dovidio JF, Gonzalez R, et al: The effects of oncologist implicit racial bias in racially discordant oncology interactions. J Clin Oncol 34: 2874-2880, 2016

7. Smedley B, Stith A, Nelson A. Unequal Treatment: Confronting Racial and Ethnic Disparities in Health Care. Washington, DC, National Academies Press, 2002

8. Association of American Medical Colleges: Underrepresented in medicine definition. https://www. aamc.org/initiatives/urm/

9. Smith MM, Rose SH, Schroeder DR, et al: Diversity of United States medical students by region compared to US census data. Adv Med Educ Pract 6 : 367-372, 2015

10. American Society of Clinical Oncology: ASCO Key Trends in Tracking Supply of and Demand for Oncologists. http://www.asco.org/sites/new-www. asco.org/files/content-files/research-and-progress/ documents/2015-cancer-care-in-america-report.pdf

11. U.S. Census Bureau: QuickFacts: United States, 2010-2015. https://www.census.gov/quickfacts/table/ PST045216/00
12. American Society of Clinical Oncology: The State of Cancer Care in America: 2016. https:// www.asco.org/research-progress/reports-studies/ cancer-care-america-2016

13. American Society of Clinical Oncology: The state of cancer care in America, 2015: A report by the American Society of Clinical Oncology. J Oncol Pract 11:79-113, 2015

14. Association of American Medical Colleges: Diversity in the Physician Workforce: Facts and Figures 2014. http://aamcdiversityfactsandfigures.org

15. Brotherton SE, Etzel SI: Graduate medical education, 2015-2016. JAMA 316:2291-2310, 2016

16. US Census Bureau: United States QuickFacts, 2010-2015. https://www.census.gov/quickfacts

17. Mattes $M D$, Patel KR, Burt LM, et al: A nationwide medical student assessment of oncology education. J Cancer Educ 31:679-686, 2016

18. Lightfoote JB, Deville C, Ma LD, et al: Diversity, inclusion, and representation: It is time to act. J Am Coll Radiol 13:1421-1425, 2016

\section{Affiliations}

Karen M. Winkfield, Wake Forest Baptist Medical Center, Winston-Salem, NC; Christopher R. Flowers, Winship Cancer Institute, Emory University; Otis W. Brawley, American Cancer Society, Atlanta, GA; Jyoti D. Patel, University of Chicago, Chicago; Patricia Robinson, Loyola University Medical Center, Maywood, IL; Gladys Rodriguez, South Texas Oncology and Hematology, San Antonio, TX; Amit Agarwal, University of Arizona, Tucson, AZ; Lori Pierce and Daniel F. Hayes, University of Michigan, Ann Arbor, MI; Edith P. Mitchell, Thomas Jefferson University Hospital, Philadelphia, PA; and Kimberly T. Head-Smith and Dana S. Wollins, American Society of Clinical Oncology, Alexandria, VA. 


\section{AUTHORS' DISCLOSURES OF POTENTIAL CONFLICTS OF INTEREST}

American Society of Clinical Oncology Strategic Plan for Increasing Racial and Ethnic Diversity in the Oncology Workforce

The following represents disclosure information provided by authors of this manuscript. All relationships are considered compensated. Relationships are self-held unless noted. I = Immediate Family Member, Inst = My Institution. Relationships may not relate to the subject matter of this manuscript. For more information about ASCO's conflict of interest policy, please refer to www.asco.org/rwc or ascopubs.org/jco/site/ifc.

Karen M. Winkfield

Consulting or Advisory Role: Novartis

\section{Christopher R. Flowers}

Consulting or Advisory Role: OptumRx, Seattle Genetics, Bayer HealthCare Pharmaceuticals, Gilead Sciences

Research Funding: Acerta Pharma (Inst), Infinity Pharmaceuticals (Inst), Onyx Pharmaceuticals (Inst), Janssen Pharmaceuticals (Inst), Gilead Sciences (Inst), Celgene (Inst), TG Therapeutics (Inst), Genentech (Inst), Pharmacyclics (Inst), AbbVie (Inst), Immune Design (Inst)

Travel, Accommodations, Expenses: Gilead Sciences, Celgene, Genentech

Jyoti D. Patel

Consulting or Advisory Role: ARIAD Pharmaceuticals, AbbVie

Gladys Rodriguez

Stock or Other Ownership: Novartis, Abbott Laboratories (I), Merck (I) Speakers' Bureau: Genentech

Patricia Robinson

No relationship to disclose

Amit Agarwal

Employment: Celgene

Consulting or Advisory Role: Millennium Pharmaceuticals, Amgen Speakers' Bureau: Millennium Pharmaceuticals, Amgen, Janssen Pharmaceuticals

\section{Lori Pierce}

Stock or Other Ownership: PFS Genomics

Patents, Royalties, Other Intellectual Property: UpToDate, PFS

Genomics
Otis W. Brawley

No relationship to disclose

\section{Edith P. Mitchell}

Honoraria: Novartis

Consulting or Advisory Role: Novartis, Pfizer

Research Funding: Genentech (Inst)

Kimberly T. Head-Smith

No relationship to disclose

Dana S. Wollins

No relationship to disclose

Daniel F. Hayes

Stock or Other Ownership: OncImmune, InBiomotion

Honoraria: Eli Lilly

Research Funding: Janssen Pharmaceuticals (Inst), AstraZeneca (Inst), Puma Biotechnology (Inst), Pfizer (Inst), Eli Lilly (Inst), Merrimack Pharmaceuticals (Inst), Parexel (Inst)

Patents, Royalties, Other Intellectual Property: Royalties from licensed technology; Diagnosis and Treatment of Breast Cancer. US Patent No. 8,790,878 B2 (July 29, 2014) for diagnosis and treatment of breast cancer (applicant proprietor, University of Michigan; D.F.H. designated as inventor/coinventor); US Patent No. 8,951,484 B2 (February 10, 2015) for circulating tumor cell-capturing techniques and devices (applicant proprietor, University of Michigan; D.F.H. designated as inventor/ coinventor); Patent No. 05725638.0-1223-US2005008602 for method of predicting progression-free and overall survival at each follow-up time point during therapy for patients with metastatic breast cancer using circulating tumor cells

Travel, Accommodations, Expenses: Janssen Pharmaceuticals 


\section{Acknowledgment}

We thank the following individuals for providing their input and participation during the strategic planning development process: Laura Castillo-Page, Brandon Blue, Pascal Jean-Pierre, Christopher Lathan, Worta McCaskill-Stevens, and Colin D. Weekes. 